\title{
Modified Asymmetrical Variable Step Size Incremental Conductance Maximum Power Point Tracking Method for Photovoltaic Systems
}

\author{
Yong Tian", Bizhong $\mathrm{Xia}^{\dagger}$, Zhihui $\mathrm{Xu}^{* *}$, and Wei Sun ${ }^{* *}$ \\ $\dagger^{* *}$ Graduate School at Shenzhen, Tsinghua University, Shenzhen, China \\ ${ }^{* *}$ Sunwoda Electronic Co. Ltd., Shenzhen, China
}

\begin{abstract}
The power-voltage $(\mathrm{P}-\mathrm{V})$ characteristic of a photovoltaic $(\mathrm{PV})$ array is nonlinear and time varying with the change in atmospheric conditions. As a result, the maximum power point tracking (MPPT) technique must be applied in PV systems to maximize the generated energy. The incremental conductance (INC) algorithm, one of the MPPT strategies, is widely used for its high tracking accuracy, good adaptability to rapidly changing atmospheric conditions, and easy implementation. This paper presents a modified asymmetrical variable step size INC MPPT method that is based on the asymmetrical feature of the P-V curve. Compared with conventional fixed or variable step size method, the proposed method can effectively improve tracking accuracy and speed. The theoretical foundation and design principle of the proposed approach are validated by the simulation and experimental results.
\end{abstract}

Keywords: Asymmetrical variable step size, Incremental conductance, Maximum power point tracking, Photovoltaic systems

\section{INTRODUCTION}

Photovoltaic (PV) generation has elicited much concern because of fossil fuel shortage and environmental deterioration. A major challenge in PV applications is that the current-voltage (I-V) characteristic is nonlinear and time varying with solar irradiation and cell temperature and results in unique maximum power point (MPP) on the power-voltage $(\mathrm{P}-\mathrm{V})$ curve. Therefore, an excellent MPP tracking (MPPT) controller that tracks MPP in real time is essential to PV systems.

Several MPPT techniques, such as open-circuit voltage [1], short-circuit current [2], perturbation and observation (P\&O) [3]-[5], hill climbing [6], [7], incremental conductance (INC) [8]-[10], incremental resistance (INR) [11], [12], neural network, and fuzzy logic control [13]-[15], have been proposed in recent years. Among them, $\mathrm{P} \& \mathrm{O}$, hill climbing, and INC are commonly used for their simplicity and easy implementation. $\mathrm{P} \& \mathrm{O}$ introduces perturbation in the

Manuscript received Jul. 4, 2013; revised Sep. 25, 2013

Recommended for publication by Associate Editor Woo-Jin Choi.

†Corresponding Author: xiabz@sz.tsinghua.edu.cn

Tel: +86-755-26036757, Fax: +86-755-26036757, Tsinghua University

* Graduate School at Shenzhen, Tsinghua University, China

** Sunwoda Electronic Co. Ltd., China operating voltage of the PV array, whereas hill climbing employs perturbation in the duty ratio of the power converter and thus makes the control structure simple and attractive [16]. The main shortcoming of these two methods is the oscillation around MPP, which results in power loss and incapacity under rapidly changing atmospheric conditions. The INC algorithm is based on the fact that the slope of the $\mathrm{P}-\mathrm{V}$ curve of the PV array is positive at the left side of MPP, zero at MPP, and negative at the right side [8]. Consequently, steady state oscillation is eliminated in theory. The INR algorithm is similar to $\mathrm{INC}$, and its primary rules can be deduced from the duality of the INC principle. A common issue in these four methods is the tradeoff between dynamic response speed and steady state accuracy. A large step size contributes to rapid dynamics but generates excessive steady state oscillations, which lead to increased power loss. However, this situation is reversed when the MPPT controller is operated with a small step size.

Several variable step size approaches for use in $\mathrm{P} \& \mathrm{O}$ [4], [5], hill climbing [6], [7], INC [8], and INR [11] have been proposed for improved performance. Although these methods can effectively reduce steady state oscillations near MPP, they slow down the dynamic response speed or lower the algorithm efficiency under rapidly changing atmospheric conditions. Furthermore, all of them do not consider the 


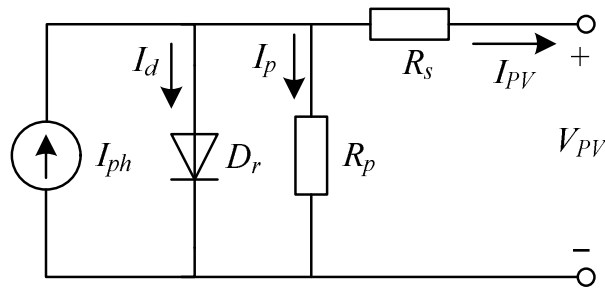

Fig. 1. Equivalent circuit of the PV cell.

asymmetrical feature of the P-V curve of the PV array. A modified asymmetrical variable step size INC MPPT method is proposed in this study. Step size is automatically adjusted according to the inherent characteristics of the PV array. When the operating point is far from MPP, the method operates with a large step size and thus accelerates the tracking process. By contrast, when the operating point is near MPP, the step size becomes extremely small that steady state oscillation is significantly reduced, thereby lowering the power loss. Moreover, the step sizes at the two sides of MPP differ. The simulation and experimental results show that the proposed method can effectively improve the dynamic and steady state performance simultaneously.

\section{PV CELL MODEL}

A PV cell consists of a $\mathrm{P}-\mathrm{N}$ junction, and its simplest equivalent circuit is shown in Fig. 1. The model is represented by an anti-parallel current source with diode $D_{r}$, and the non-idealities are represented by parallel resistance $R_{p}$ and series resistance $R_{s}[17]$.

The relationship between output current $I_{P V}$ and output voltage $V_{P V}$ can be expressed as follows [18]:

$$
I_{P V}=I_{p h}-I_{0}\left(\exp \left(\frac{q\left(V_{P V}+I_{P V} R_{S}\right)}{A K T}\right)-1\right)-\frac{V_{P V}+I_{P V} R_{S}}{R_{p}}
$$

where $R_{p}$ and $R_{s}$ are the equivalent parallel resistance and series resistance of the cell (usually $R_{p}>10 \mathrm{k} \Omega$ and $R_{s}<1 \Omega$ ), respectively; $q$ is the electronic charge $\left(q=1.6 \times 10^{-19} \mathrm{C}\right) ; I_{p h}$ is the photo-current; $I_{0}$ is the reverse saturation current; $K$ is the Boltzman constant $\left(K=1.38 \times 10^{-23} \mathrm{~J} / \mathrm{K}\right) ; T$ is cell temperature; and $A$ is the ideal factor of the diode.

The following two conditions are assumed to simplify the analysis.

(1) $R_{p}$ is large; thus, $\left(V_{P V}+R_{s} I_{P V}\right) / R_{p}$ can be ignored.

(2) $R_{s}$ is small; thus, $I_{p h}=I_{s c}$.

Based on the two assumptions above, the relationship between $I_{P V}$ and $V_{P V}$ can be simplified as follows [19]:

$$
I_{P V}=I_{s c}\left(1-C_{1}\left(\exp \left(\frac{V_{P V}}{C_{2} V_{o c}}\right)-1\right)\right)
$$

where

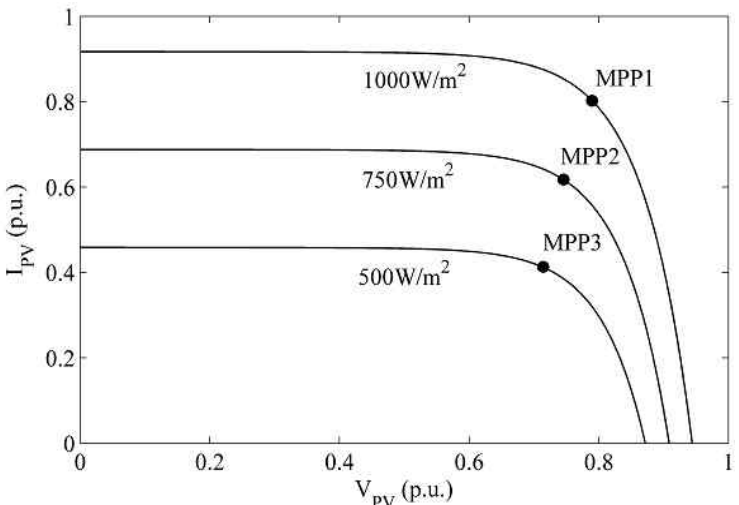

(a)

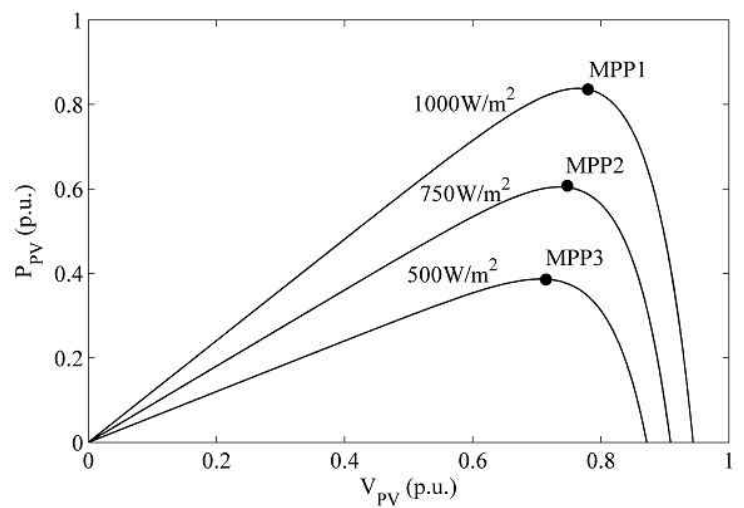

(b)

Fig. 2. Normalized characteristics of the PV array. (a) Variation of I-V characteristics with solar irradiation at $25^{\circ} \mathrm{C}$. (b) Variation of $\mathrm{P}-\mathrm{V}$ characteristics with solar irradiation at $25^{\circ} \mathrm{C}$.

$$
\begin{aligned}
& C_{1}=\left(1-\frac{I_{m}}{I_{s c}}\right) \exp \left(-\frac{V_{m}}{C_{2} V_{o c}}\right) \\
& C_{2}=\left(\frac{V_{m}}{V_{o c}}-1\right) / \ln \left(1-\frac{I_{m}}{I_{s c}}\right)
\end{aligned}
$$

where $V_{o c}$ is the open-circuit voltage, $I_{s c}$ is the short-circuit current, $V_{m}$ is the peak power voltage, and $I_{m}$ is the peak power current.

When irradiation $S$ and temperature $T$ are changed, the parameters $V_{o c}, I_{s c}, V_{m}$, and $I_{m}$ can be updated by [19]

$$
\begin{gathered}
V_{o c}=V_{o c r}\left(1-K_{V T} \Delta T\right) \ln \left(\exp (1)+K_{V S} \Delta S\right) \\
I_{s c}=I_{s c r}\left(1+K_{I T} \Delta T\right) \frac{S}{S_{r e f}}, \\
V_{m}=V_{m r}\left(1-K_{V T} \Delta T\right) \ln \left(\exp (1)+K_{V S} \Delta S\right) \\
I_{m}=I_{m r}\left(1+K_{I T} \Delta T\right) \frac{S}{S_{r e f}}
\end{gathered}
$$

where

$$
\begin{aligned}
\Delta T & =T-T_{r e f} \\
\Delta S & =\frac{S}{S_{r e f}}-1 \\
K_{I T} & =0.0025 /{ }^{o} \mathrm{C} . \\
K_{V S} & =0.5 \\
K_{V T} & =0.00288 /{ }^{\circ} \mathrm{C}
\end{aligned}
$$


A PV array generally comprises a number of PV cells connected either in series or parallel. The normalized output characteristics of the PV array are shown in Fig. 2 based on the aforementioned mathematical model. The I-V characteristic of the PV cell is nonlinear and time varying with irradiation and thus results in unique MPP on its $\mathrm{P}-\mathrm{V}$ curve. An efficient MPPT control strategy that quickly tracks MPP is therefore essential to PV systems.

\section{MPPT CONTROL STRATEGY}

A variety of MPPT approaches have been proposed to maximize the output power of a PV array. Among them, the INC MPPT method is the most widely used for its high tracking accuracy, good adaptability to rapidly changing atmospheric conditions, and easy implementation. Step size is invariable in the basic INC algorithm. Thus, a large step size contributes to fast dynamics but generates excessive steady state oscillations that lead to power loss. This situation is reversed when the step size is small. Thus, a satisfying tradeoff between dynamics and steady state oscillations must be made in the fixed step size INC MPPT algorithm. Such design dilemma can be addressed by the variable step size strategy.

In most practical applications, a DC-DC converter is placed between the PV array and load to implement MPPT. The output power of a PV array is adjusted by directly changing the duty cycle of the power converter to simplify the control complexity. Note that $D(k), V(k), I(k)$, and $P(k)$ are the power converter duty cycle, PV array output voltage, current, and power at time $k$, respectively. The derivative of power to voltage $(d P / d V)$ of a $\mathrm{PV}$ array is employed as a suitable parameter to regulate the variable increment in the INC MPPT algorithm. A typical variable step size INC MPPT is as follows [20]:

$$
\begin{aligned}
D(k) & =D(k-1) \pm N\left|\frac{d P}{d V}\right| \\
& =D(k-1) \pm N\left|\frac{\Delta P}{\Delta V}\right| \\
& =D(k-1) \pm N\left|\frac{P(k)-P(k-1)}{V(k)-V(k-1)}\right|
\end{aligned}
$$

where coefficient $N$ is the scaling factor used to adjust the step size automatically.

For the strategy shown in Equation (7), the tracking performance is essentially decided by scaling factor $N$. Therefore, selecting an optimal scaling factor is crucial to such method. However, manual adjustment of the scaling factor is inefficient and tedious, and the acquired optimal value may only be valid for a given system and certain operating conditions [20]. As an effective solution to such design dilemma, a simple method to determine the scaling factor was presented in [8]. To guarantee the convergence of

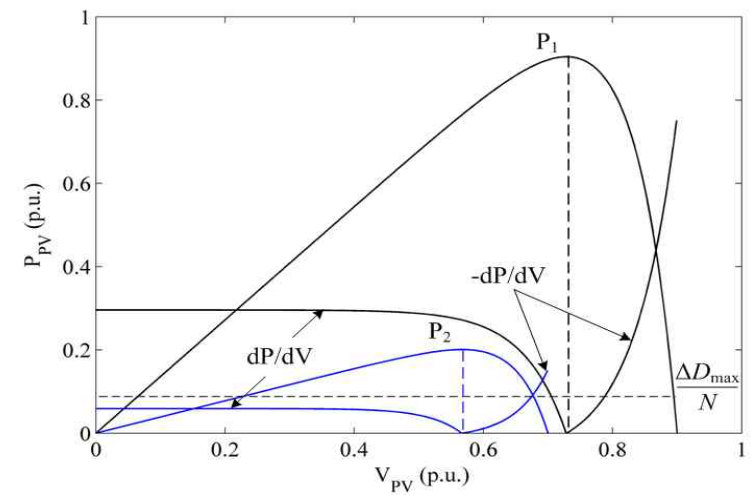

Fig. 3. Slope of power versus voltage under different irradiation conditions.

the MPPT update rule, the scaling factor must meet the following inequality:

$$
N<\Delta D_{\max } /\left|\frac{d P}{d V}\right|_{\text {fixed step }=\Delta D_{\max }}
$$

where $\Delta D_{\max }$ is the largest step size.

Equation (8) provides simple guidance to determine the range of scaling factor $N$ for the variable step size INC MPPT algorithm. If Equation (8) is not satisfied, the algorithm will operate with fixed step size $\Delta D_{\max }$. The scaling factor acquired by this method cannot ensure that the system is kept in the variable step size mode while irradiation is rapidly changed. For example, under the condition that power $P_{1}$ is larger than power $P_{2}$ as shown in Fig. 3 [11], the system for curve $P_{1}$ almost cannot operate in the variable step size mode with scaling factor $N$ obtained from Equation (8). $D_{\max } / N$ is significantly small that $|d P / d V|$ is extremely large to maintain the step size within the variable step size range. However, the system for curve $P_{2}$ will always be in the variable step size mode with the same scaling factor $N$, which seriously reduces the system response speed. Consequently, a "dead band" [11] for the fixed scaling factor method is generated. The variable step size INC MPPT algorithm proposed in [8] experiences difficulty in obtaining optimal scaling factor $N_{\text {opt }}$, which is suitable for the two power curves in the "dead band."

A variable step size INR MPPT algorithm has been proposed to overcome these problems [11]. However, this algorithm does not consider the asymmetrical feature of the $\mathrm{P}-\mathrm{V}$ curve of the PV array. Moreover, current $I$ and current variation $\Delta I$ are used as the denominators in this algorithm; this condition requires a high-precision current sensor and will increase the hardware cost. A modified asymmetrical variable step size INC MPPT algorithm is presented in this study to improve dynamic response speed and steady state accuracy. The major differences between the proposed method and others are as follows.

1) Based on the asymmetrical characteristic of the $P-V$ curve of the PV array, an asymmetrical step size strategy is adopted to accelerate the dynamic response. Hence, step sizes may differ at the two sides of MPP despite the similar power 
variation.

2) According to the different operating points of a system, the algorithm can be implemented in two modes, namely, asymmetrical fixed step size mode and adaptive variable step size mode.

3) A function marked as $F$, whose value is the product of the PV array output power and the absolute value of the PV array power derivative $(|d P / d V|)$, is employed to switch the step size modes as provided by

$$
F=P_{P V} *\left|\frac{d P}{d V}\right| \text {. }
$$

4) The proposed method can consistently ensure that the system operates in fixed and variable step size modes although irradiation is rapidly changed. A novel and simple method is introduced to avoid the "dead band" problem for the scaling factor in [8] as provided by

$$
\begin{gathered}
S_{k}=\alpha \cdot \frac{|d P / d V|_{k}}{\beta+|d P / d V|_{k}} \\
S_{1 k}=S_{k} \cdot \Delta D_{\max 1} \\
S_{2 k}=S_{k} \cdot \Delta D_{\max 2}
\end{gathered}
$$

where $\alpha$ is a scaling factor utilized to scale down the step size; $\beta$ is a factor utilized to adjust the slope of $S_{k}$; and $\Delta D_{\max 1}$ and $\Delta D_{\max 2}$ are the largest step sizes at the left and right sides of MPP, respectively. The value of $\alpha$ should be maintained in the range of $[0,1]$ and $\beta$ should be a positive number to always make variable step size $S_{1 k}$ or $S_{2 k}$ less than $\Delta D_{\max 1}$ or $\Delta D_{\max 2}$ at each side of MPP. Compared with the method proposed in [11], the current proposed method is simpler and easier to implement in microprocessors because the complicated square root operation is canceled.

PV array output power $P_{P V}$, the absolute value of the slope of output power versus output voltage $(|d P / d V|)$, and the product of the output power and its slope $\left(P_{P V}{ }^{*}|d P / d V|\right)$ are shown in Fig. 4 to illustrate the principle of the proposed algorithm clearly. The figure indicates that $F$ has two extreme values $\left(M_{1}\right.$ and $\left.M_{2}\right)$ that correspond to two voltage values $\left(V_{1}\right.$ and $\left.V_{2}\right)$ at the two sides of MPP. The algorithm operates in the variable step size mode when the PV array output voltage is between $V_{1}$ and $V_{2}$. Otherwise, the algorithm operates in the asymmetrical fixed step size mode.

The $\mathrm{P}-\mathrm{V}$ characteristic curve of a PV array is asymmetrical as shown in Fig. 5.

Fig. 5 shows that the output voltage of the PV array increases from $V_{1}$ to $V_{m}$ when the output power varies from $P_{1}$ to $P_{m}$ at the left side of MPP; however, the value decreases from $V_{2}$ to $V_{m}$ when the output power varies from $P_{2}$ to $P_{m}$ at the other side. When $P_{1}$ equals $P_{2}$, the following relationships can be obtained.

$$
\begin{aligned}
& P_{m}-P_{1}=P_{m}-P_{2} \\
& V_{m}-V_{1}>V_{m}-V_{2}
\end{aligned}
$$

According to Equations (13) and (14), if the tracking time

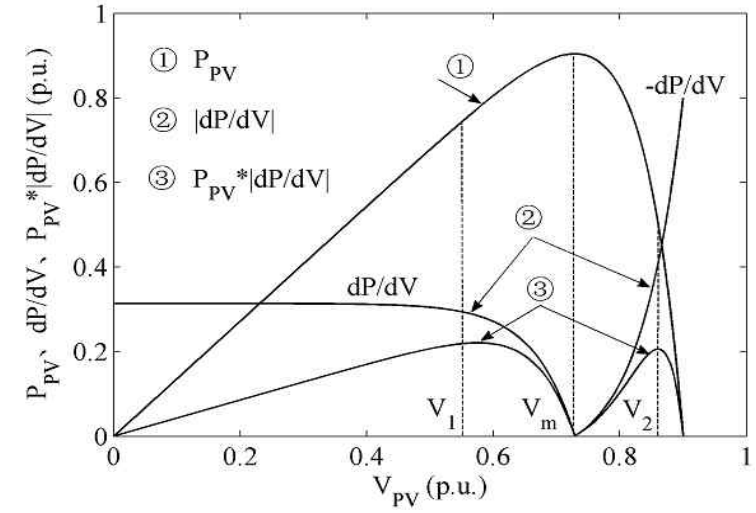

Fig. 4. Normalized power, the slope of power versus voltage, and the product of power and its slope.

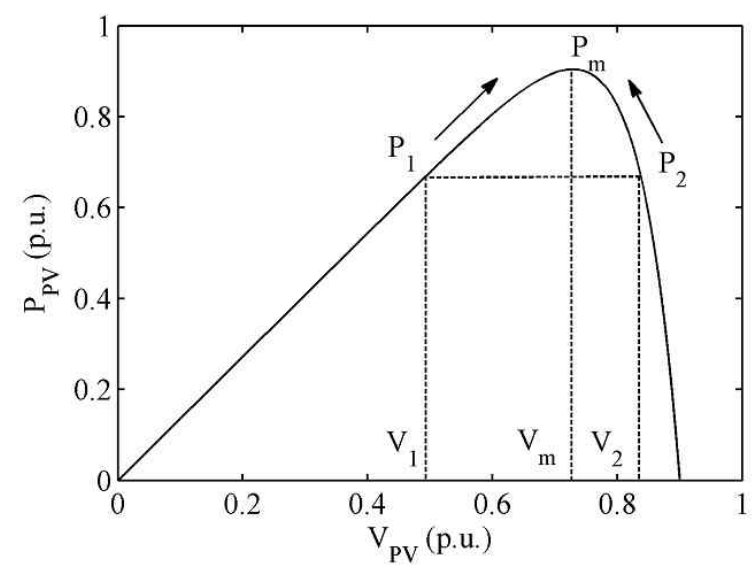

Fig. 5. Normalized power and the slope of power versus voltage.

from $P_{1}$ to $P_{m}$ equals that from $P_{2}$ to $P_{m}$, the following inequality must be met.

$$
\Delta D_{1}>\Delta D_{2}
$$

where $\Delta D_{1}$ and $\Delta D_{2}$ are the step sizes at the left and right sides of MPP, respectively.

Consequently, the proposed method can be formulated by

$$
\begin{cases}d P / d V>0 \text { and } \Delta F / \Delta V \geq 0 & \text { Fixed step size } \Delta D_{\text {con } 1} \\ d P / d V>0 \text { and } \Delta F / \Delta V<0 & \text { Variable step size } \Delta D_{\mathrm{var} 1} \\ d P / d V<0 \text { and } \Delta F / \Delta V>0 & \text { Variable step size } \Delta D_{\mathrm{var} 2} \\ d P / d V<0 \text { and } \Delta F / \Delta V \leq 0 & \text { Fixed step size } \Delta D_{\text {con } 2}\end{cases}
$$

The flowchart of the proposed asymmetrical variable step size INC MPPT algorithm is shown in Fig. 6. $S_{1 \mathrm{k}}$ and $S_{2 \mathrm{k}}$ are the two scaling factors utilized to automatically adjust the step size at the left and right sides of MPP, respectively. $\Delta D_{\max 1}$ and $\Delta D_{\max 2}$ are the maximum step sizes at the two sides. For the left side of MPP, if $\Delta F / \Delta V \geq 0$, the system will operate in the fixed step size mode with the upper limited $\Delta D_{\max 1}$; otherwise, the system will operate in the variable step size mode with adaptive step size $S_{1 \mathrm{k}}$. For the right side of MPP, if $\Delta \mathrm{F} / \Delta \mathrm{V} \leq 0$, the system will operate in the fixed step size mode with the upper limited $\Delta D_{\max 2}$; otherwise, the system will operate in the variable step size mode with adaptive step size $S_{2 \mathrm{k}}$. 


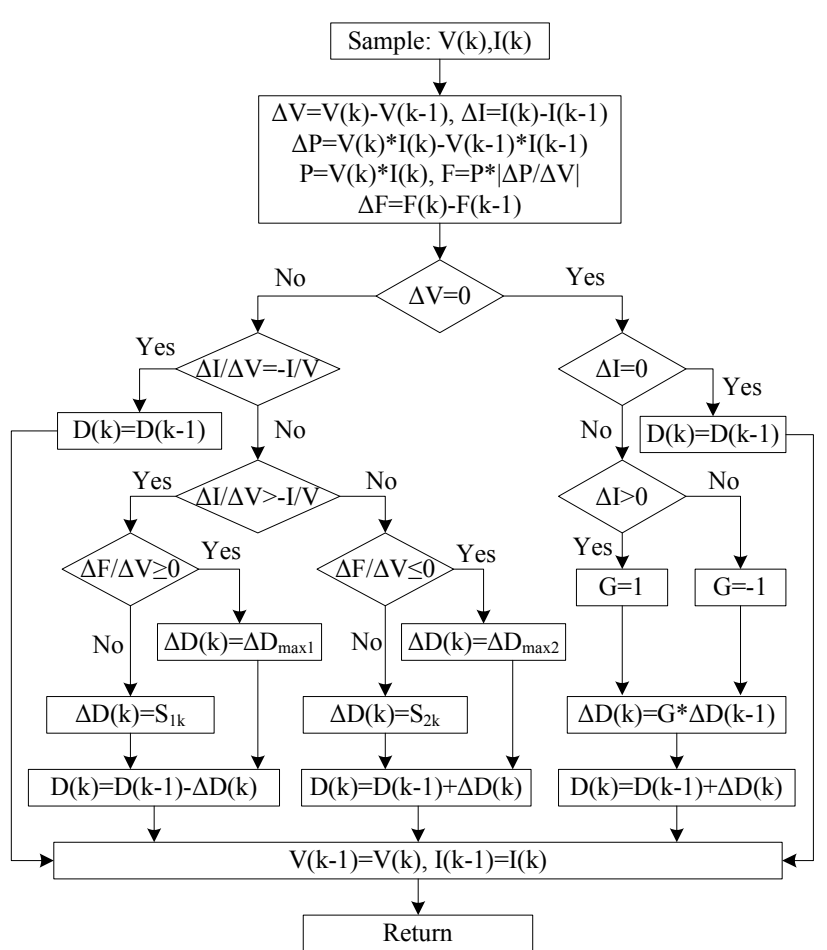

Fig. 6. Flowchart of the proposed asymmetrical variable step size INC MPPT algorithm.

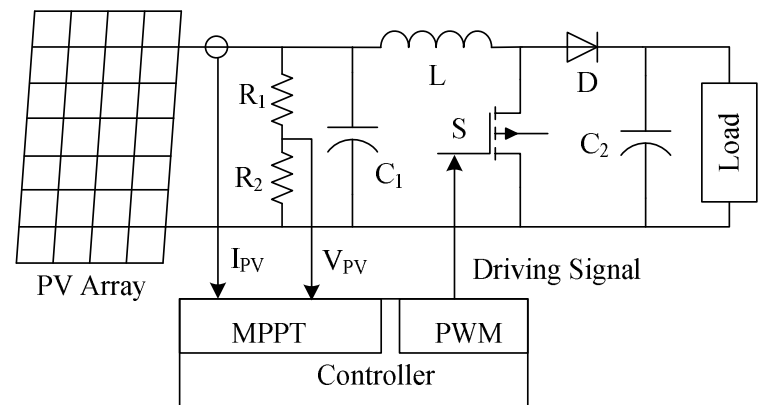

Fig. 7. Block diagram of the MPPT system.

\section{SiMULATION AND EXPERIMENTAL ANALYSIS}

A stand-alone PV system with an MPPT controller (shown in Fig. 7) is developed in this section to verify the feasibility of the proposed modified asymmetrical variable step size INC MPPT method. A boost converter placed between the PV array and the load is employed as the MPP tracker.

\section{A. Simulation Results and Analysis}

The proposed strategy is implemented through the MATLAB/SIMULINK simulation model shown in Fig. 8. The system parameters for the simulation are provided in Table I. A PV array is modeled using the basic mathematical equations introduced in Section II. The HYS-100WM-36V monocrystalline silicon solar cell whose characteristics are listed in Table II is employed for the PV array model in the simulation.

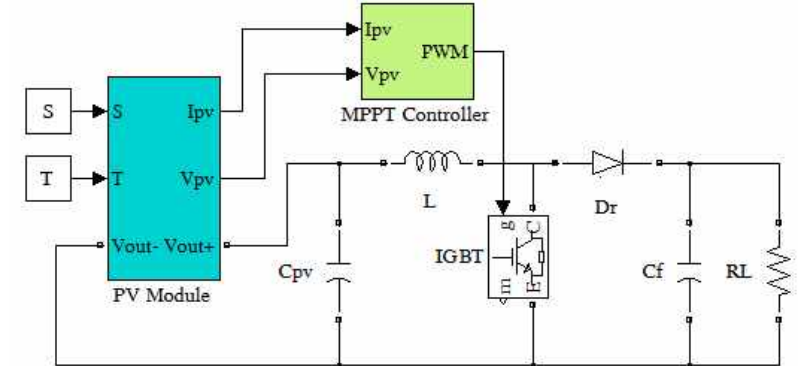

Fig. 8. Simulation model.

TABLE I

PARAMETERS For SiMULATION

\begin{tabular}{lc}
\hline \multicolumn{1}{c}{ Parameters } & Value \\
\hline Input filter capacitance $\left(C_{p v}\right)$ & $470 \mu \mathrm{F}$ \\
Boost inductance $(L)$ & $600 \mu \mathrm{H}$ \\
Output filter inductance $\left(C_{f}\right)$ & $470 / 2 \mu \mathrm{F}$ \\
Load resistance $\left(R_{L}\right)$ & $50 \Omega$ \\
Switching frequency $(f)$ & $20 \mathrm{kHz}$ \\
\hline
\end{tabular}

TABLE II

Characteristics Of Hys-100wm-36v Solar Cell

\begin{tabular}{lc}
\hline \multicolumn{1}{c}{ Parameters } & Value \\
\hline Open-circuit voltage $\left(V_{o c}\right)$ & $42.48 \mathrm{~V}$ \\
Short-circuit current $\left(I_{s c}\right)$ & $3.21 \mathrm{~A}$ \\
Peak power voltage $\left(V_{m}\right)$ & $35.28 \mathrm{~V}$ \\
Peak power current $\left(I_{m}\right)$ & $2.84 \mathrm{~A}$ \\
Peak power $\left(P_{m}\right)$ & $100 \mathrm{~W}$ \\
Reference cell temperature $\left(T_{r e f}\right)$ & $25^{\circ} \mathrm{C}$ \\
Reference irradiation at $T_{r e f}\left(S_{r e f}\right)$ & $1000 \mathrm{~W} / \mathrm{m}^{2}$ \\
\hline
\end{tabular}

The simulations are implemented with the same configurations to compare the performance of the proposed algorithm with that of the traditional fixed step size INC MPPT method. The sampling period for the waveform display is set as $0.0001 \mathrm{~s}$. The sampling period for the MPPT algorithm and the step size cycle is $0.01 \mathrm{~s}$. Irradiation abruptly decreased from $1000 \mathrm{~W} / \mathrm{m}^{2}$ to $500 \mathrm{~W} / \mathrm{m}^{2}$ at $0.5 \mathrm{~s}$ and then increased back to $1000 \mathrm{~W} / \mathrm{m}^{2}$ at $1.0 \mathrm{~s}$. The simulation results of the INC MPPT method with fixed step sizes of 1.0 and 2.0 are shown in Figs. 9 and 10, respectively.

For the proposed asymmetrical variable step size INC MPPT method, the appropriate maximum step sizes $\Delta D_{\max 1}$ and $\Delta D_{\max 2}$ are set as 2.5 and 2.0, respectively; scaling factor $\alpha$ is set as 0.8 , and factor $\beta$ is set as 0.5 . The simulation results of the proposed INC MPPT algorithm are shown in Fig. 11.

Figs. 9 and 10 reveal that compared with the MPPT algorithm with a fixed step size of 1.0 shown in Fig. 9(a), the MPPT algorithm with a fixed step size of 2.0 shown in Fig. 10(a) generates a faster dynamic response but more severe 


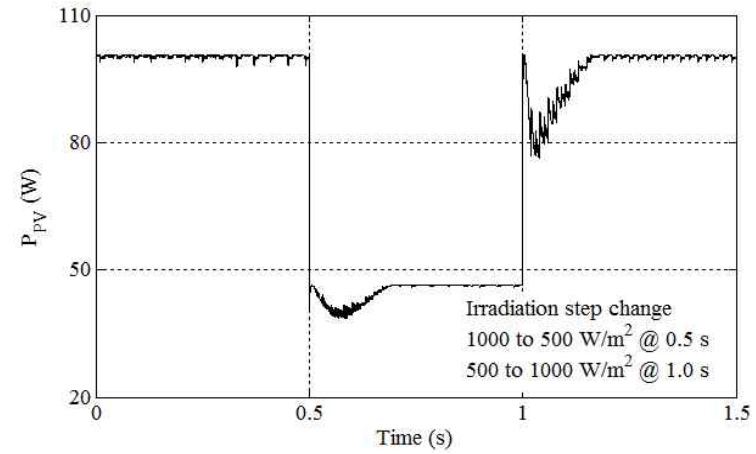

(a)

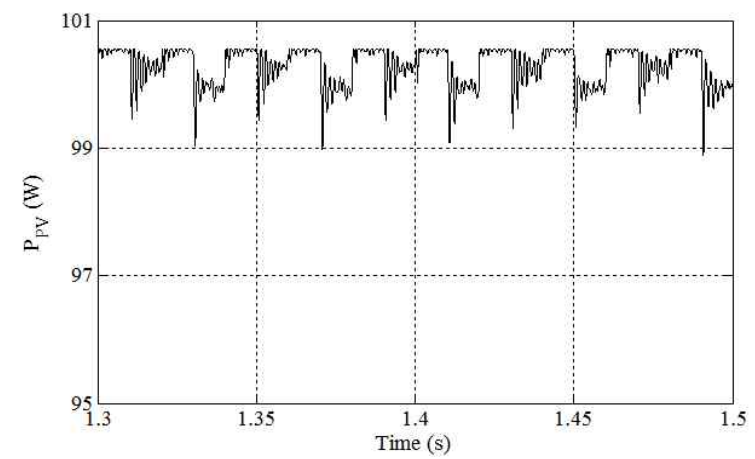

(b)

Fig. 9. PV array output power waveforms of INC MPPT with a fixed step size of 1.0. (a) Complete waveform and (b) local enlarged waveform.

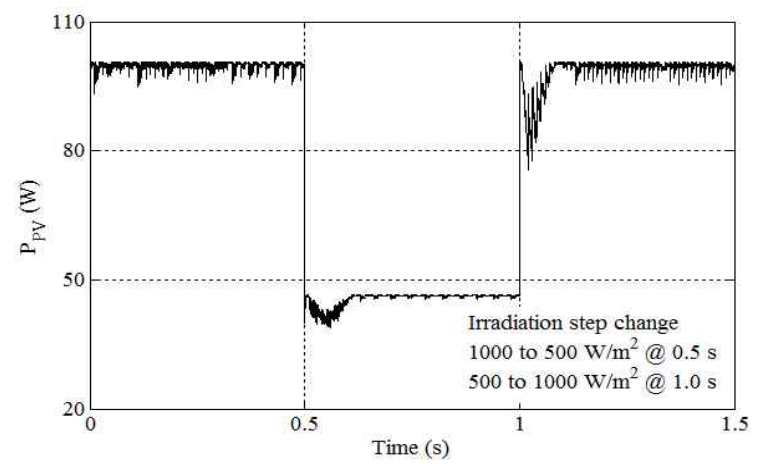

(a)

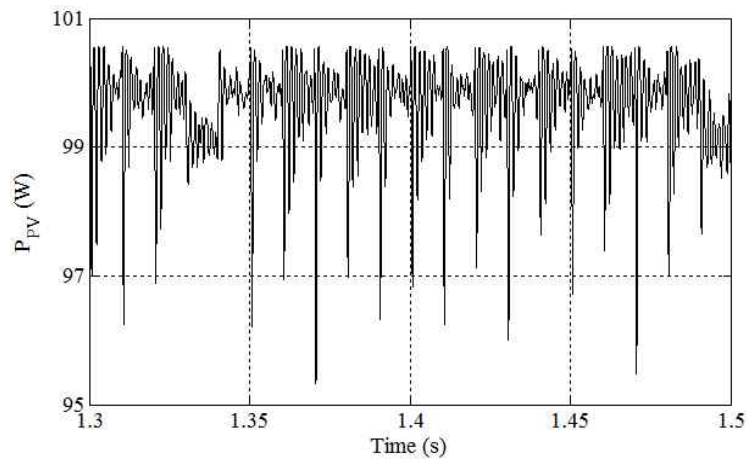

(b)

Fig. 10. PV array output power waveforms of INC MPPT with a fixed step size of 2.0. (a) Complete waveform and (b) local enlarged waveform.

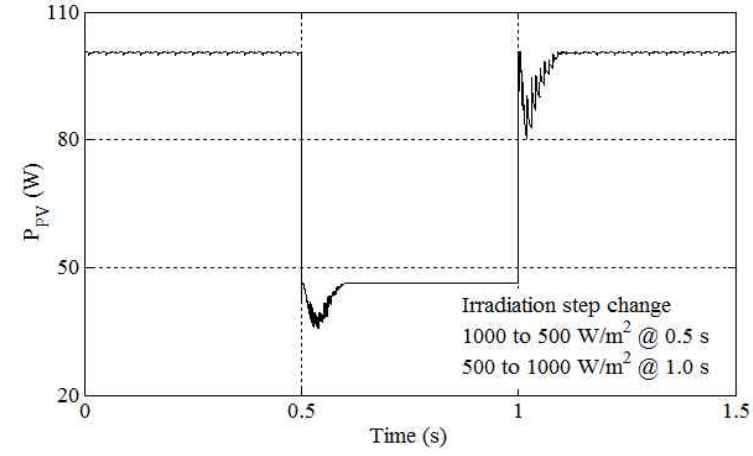

(a)

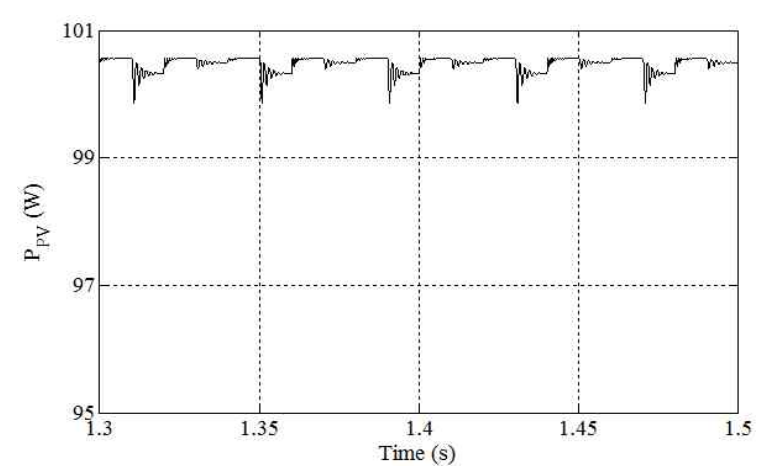

(b)

Fig. 11. PV array output power waveforms of the asymmetrical variable step size INC MPPT algorithm. (a) Complete waveform and (b) local enlarged waveform.

steady state oscillations. Under the step-changed irradiation conditions, the dynamic response time with a fixed step size of 2.0 is only several step size cycles and can be further shortened if a relatively larger step size is used. A well-known dilemma for the fixed step size INC MPPT method is that a fast response leads to low efficiency as proven by the local enlarged steady state power shown in Figs. 9(b) and 10(b). Fig. 9(b) indicates that the ripple power is less than $1.8 \mathrm{~W}$ (peak-to-peak value) for the fixed step size of 1.0. However, the value increased to almost $6 \mathrm{~W}$ for the fixed step size of 2.0 as shown in Fig. 10(b). Figure 11 shows that the proposed asymmetrical variable step size INC MPPT method can efficiently deal with the tradeoff between dynamic response speed and steady state accuracy. The steady state oscillations are almost eliminated because of the extremely small $|d P / d V|$ around MPP as shown in Fig. 11(b); the ripple power is less than $1.0 \mathrm{~W}$. The dynamic performance is obviously better than that with a fixed step size of 1.0 .

\section{B. Experimental Results and Discussion}

A laboratory prototype, shown in Fig. 12, is constructed to verify the proposed asymmetrical variable step size INC MPPT method in practice. Solar array simulator model $62150 \mathrm{H}-1000 \mathrm{~S}(15 \mathrm{~kW}, 1000 \mathrm{~V} / 15 \mathrm{~A})$ from Chroma Group is used as the PV array. A stand-alone boost converter is placed 


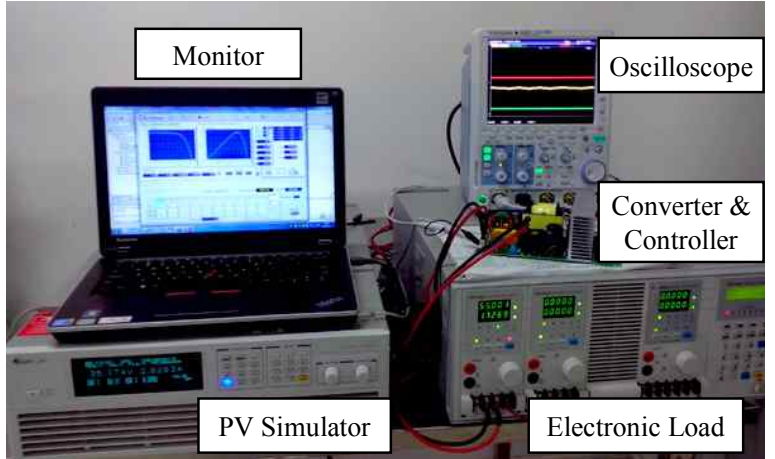

Fig. 12. Prototype of the MPPT system.

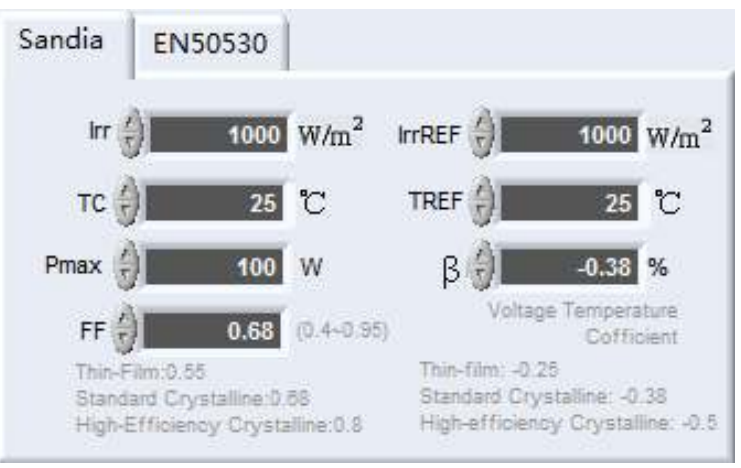

(a)

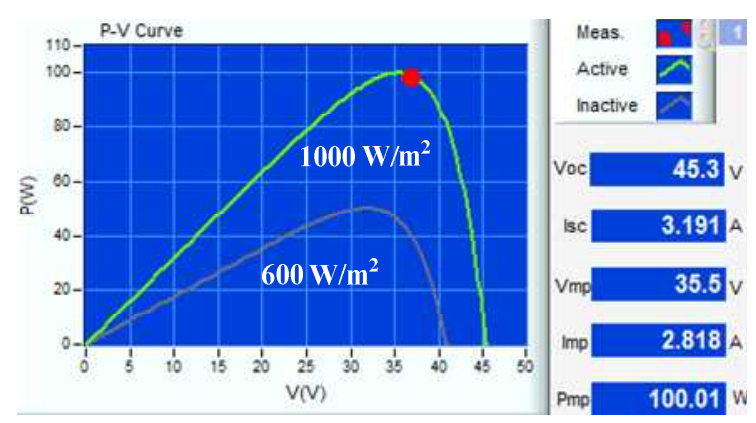

(b)

Fig. 13. Simulator configurations and output curves. (a) Sandia parameters and (b) output $\mathrm{P}-\mathrm{V}$ curves.

between the solar simulator and the load to track the peak power; its specifications are similar to those shown in Table I. TMS320F28335 DSP is selected as the system controller. The system should reach the steady state in each MPPT cycle $[4,8]$. Therefore, the MPPT sampling period and the step size cycle selected for the experiment are $0.1 \mathrm{~s}$ and $0.5 \mathrm{~s}$ (five times of the sampling period; the value of $V(k)$ or $I(k)$ used to calculate $\Delta D(k)$ is the average value of the five sampling values), respectively.

In the simulator $62150 \mathrm{H}-1000 \mathrm{~S}$, the I-V mathematical expressions suggested by Sandia National Lab and the EN50530 regulation are employed to edit various I-V curves, the conversion efficiency of the PV inverter, and MPPT performance. The Sandia model is selected in this study, and the set parameters are shown in Fig. 13(a). The I-V program edit function is utilized to simulate sunlight and temperature

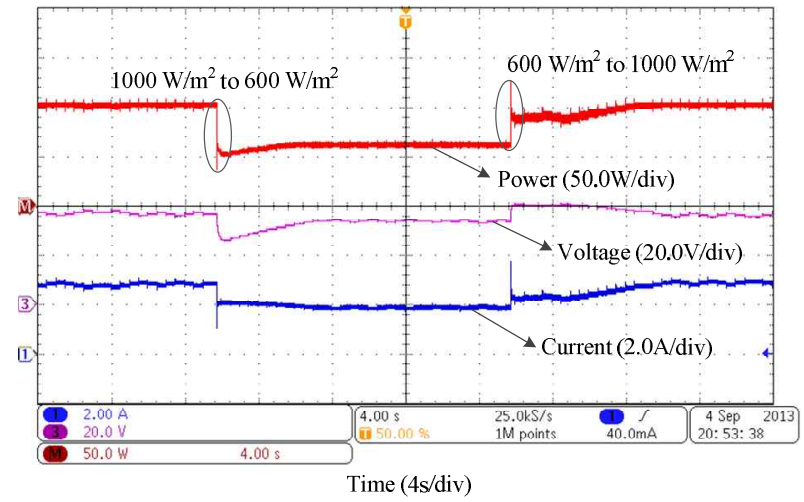

(a)

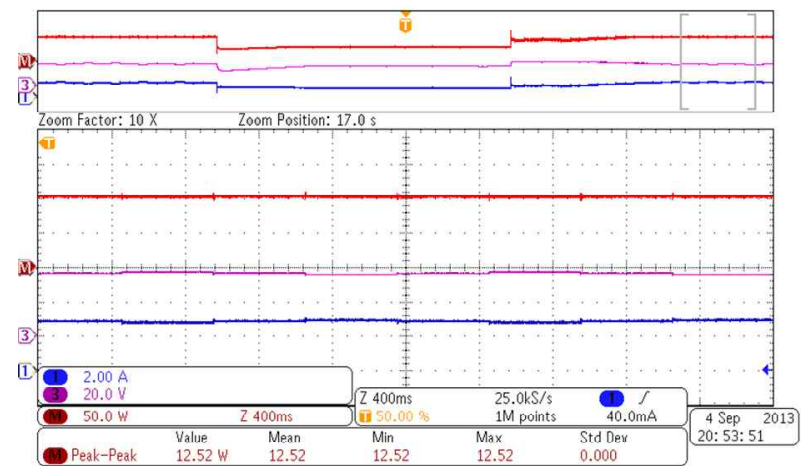

(b)

Fig. 14. PV array output power, voltage, and current waveforms of the INC MPPT algorithm with a fixed step size of 1.0. (a) Complete waveforms and (b) local enlarged waveforms.

from dawn to dusk. The output $\mathrm{P}-\mathrm{V}$ curves are shown in Fig. 13(b).

The PV array output waveforms for the fixed step size INC MPPT algorithm when the irradiation is changed abruptly are shown in Figs. 14 and 15. The corresponding PV array output power, voltage, and current waveforms of the proposed variable step-size INR MPPT algorithm are shown in Fig. 16. The sampling and step size cycles are set to have similar values to compare the performance of these two methods fairly.

According to Figs. 14, 15, and 16, the asymmetrical variable step size INC MPPT algorithm reaches MPP within $4 \mathrm{~s}$ (eight times of the step size cycle) when irradiation is suddenly changed from $1000 \mathrm{~W} / \mathrm{m}^{2}$ to $600 \mathrm{~W} / \mathrm{m}^{2}$; the algorithm requires $7 \mathrm{~s}$ (14 times of the step size cycle) to track MPP under the same condition with a fixed step size of 1.0. Although a large step size can obviously shorten the tracking time in the fixed step size method as shown in Fig. 15 , it aggravates the undesirable steady state oscillation. The above figures reveal that the asymmetrical variable step size INC MPPT algorithm presents better dynamic performance than the fixed step size method under the same steady state accuracy. However, the steady state ripple power values tested by the oscilloscope for a fixed step size of 1.0, a fixed step size of 2.0 , and the asymmetrical variable step size 


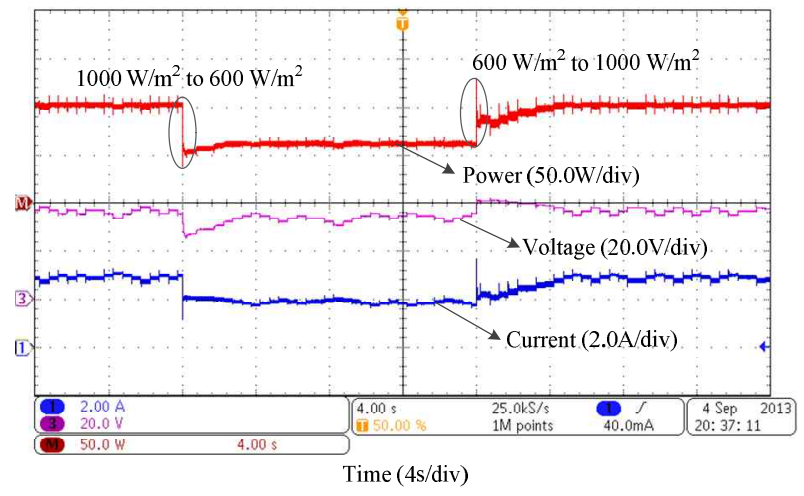

(a)

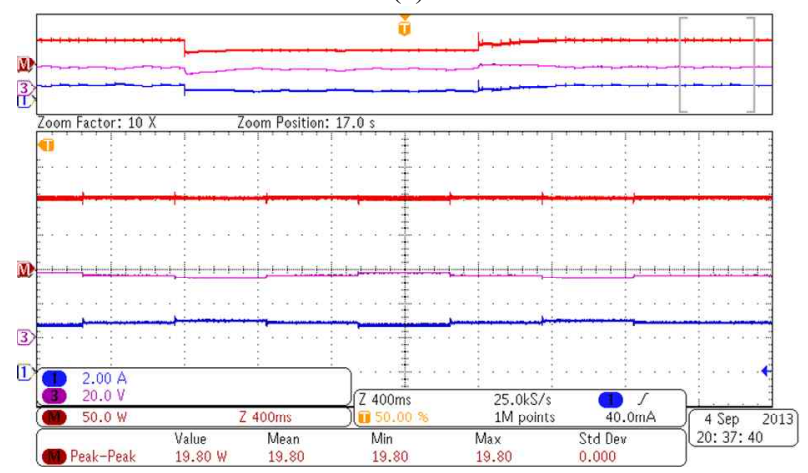

(b)

Fig. 15. PV array output power, voltage, and current waveforms of the INC MPPT algorithm with a fixed step size of 2.0. (a) Complete waveforms and (b) local enlarged waveforms.

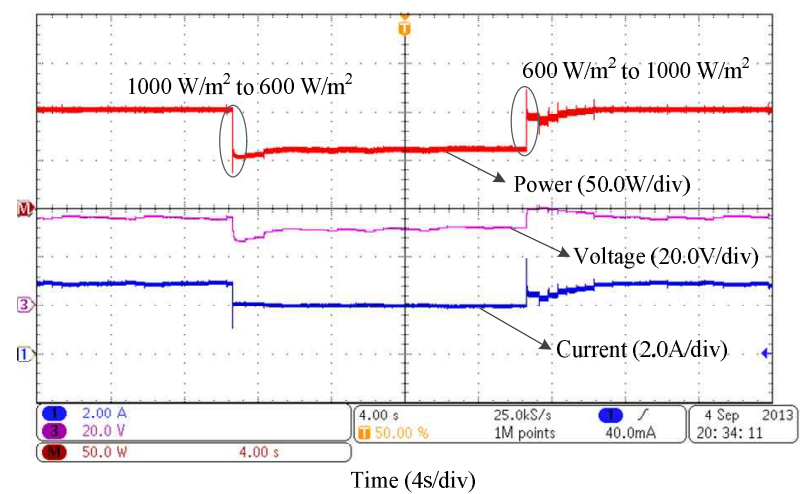

(a)

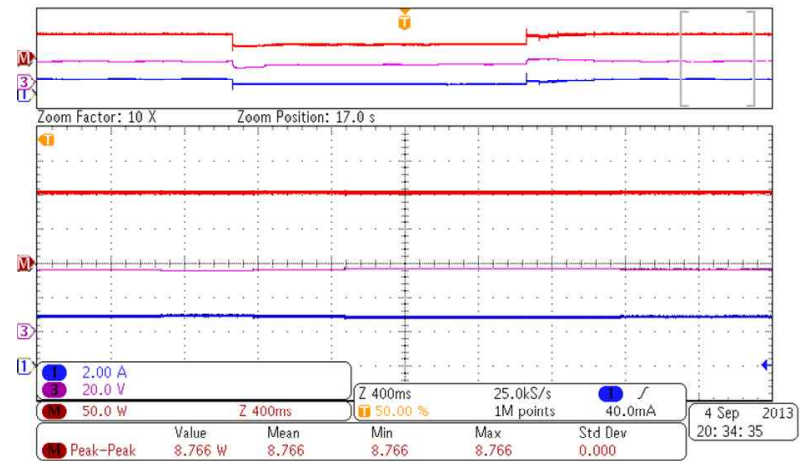

(b)

Fig. 16. PV array output power, voltage, and current waveforms of asymmetrical variable step size INC MPPT algorithm. (a) Complete waveforms and (b) local enlarged waveforms. method are 12.52, 19.8, and 8.766 W (peak-to-peak value), respectively. Hence, the asymmetrical variable step size algorithm has the best steady state performance. The proposed asymmetrical variable step size INC MPPT algorithm is a better choice under practical operating conditions. In addition, the other methods require much time to track MPP when irradiation is changed from $600 \mathrm{~W} / \mathrm{m}^{2}$ to $1000 \mathrm{~W} / \mathrm{m}^{2}$. For the two INC MPPT algorithms, the track speed is low under increasing irradiation than that under decreasing irradiation. This condition is another problem to be solved.

\section{CONCLUSIONS}

A novel asymmetrical variable step size INC MPPT algorithm was developed in this study. The algorithm considers the asymmetrical feature of the $\mathrm{P}-\mathrm{V}$ curve of a PV array. This method can improve the dynamic and steady state performance of the PV system. The mathematical mode and output characteristics of the PV cell based on the equivalent circuit were analyzed. The design rule of the asymmetrical variable step size INC MPPT method was discussed in detail, and an implementation process was provided. A MATLAB/SIMULINK simulation model and a laboratory prototype that employs a DSP microcontroller were constructed to implement the proposed asymmetrical variable step size and fixed step size INC MPPT methods. The simulation and experimental results verify the feasibility and effectiveness of the proposed method.

\section{ACKNOWLEDGMENT}

This work was supported by the China Postdoctoral Science Foundation Funded Project (2013M540941) and the Shenzhen Key Laboratory of LED Packaging Funded Project (NZDSY20120619141243215).

\section{REFERENCES}

[1] N. Mutoh, T. Matuo, K. Okada, and M. Sakai, "Prediction-data based maximum-power-point-tracking method for photovoltaic power generation systems," in Proc. 33rd Annu. IEEE Power Electron. Spec. Conf., pp. 1489-1494, 2002.

[2] K. Kobayashi, H. Matsuo, and Y. Sekine, "A novel optimum operating point tracker of the solar cell power supply system," in Proc. 35th Annu. IEEE Power Electron. Spec. Conf., pp. 2147-2151, 2004.

[3] N. Femia, G. Petrone, G. Spagnuolo, and M. Vitelli, "A technique for improving P\&O MPPT performances of double-stage grid-connected photovoltaic systems," IEEE Trans. Ind. Electron., Vol. 56, No. 11, pp. 4473-4482, Nov. 2009.

[4] N. Fermia, D. Granozio, G. Petrone, and M. Vitelli, "Predictive \& adaptive MPPT perturb and observe method," 
IEEE Trans. Aerosp. Electron Syst., Vol. 43, No. 3, pp. 934-950, Jul. 2007.

[5] A. K. Abdelsalam, A. M. Massoud, S. Ahmed, and P. N. Enjeti, "High-Performance adaptive perturb and observe MPPT technique for photovoltaic-based microgrids," IEEE Trans. Power Electron., Vol. 26, No. 4, pp. 1010-1021, Apr. 2011.

[6] S. Jain and V. Agarwal, "A new algorithm for rapid tracking of approximate maximum power point in photovoltaic systems," IEEE Trans. Power Electron. Lett., Vol. 2, No. 1, pp. 16-19, Mar. 2004

[7] W. Xiao and W. G. Dunford, "A modified adaptive hill climbing MPPT method for photovoltaic power systems," in Proc. 35th Annu. IEEE Power Electron. Spec. Conf., pp. 1957-1963, 2004.

[8] F. Liu, S. Duan, F. Liu, B. Liu, and Y. Kang, "A variable step size INC MPPT method for PV systems," IEEE Trans. Ind. Electron., Vol. 55, No. 7, pp. 2622-2628, Jul. 2008

[9] A. Safari and S. Mekhilef, "Simulation and hardware implementation of incremental conductance MPPT with direct control method using cuk converter," IEEE Trans. Ind. Electron., Vol. 58, No. 4, pp. 1154-1161, Apr. 2011.

[10] P. E. Kakosimos and A. G. Kladas, "Implementation of photovoltaic array MPPT through fixed step predictive control technique," Renewable Energy, Vol. 36, pp. 2508-2514, 2011.

[11] Q. Mei, M. Shan, L. Liu and J. M. Guerrero, "A novel improved variable step-size incremental-resistance MPPT method for PV systems," IEEE Trans. Ind. Electron., Vol. 58, No. 6, pp. 2427-2434, Jun. 2011.

[12] E. M. Ahmed and M. Shoyama, "Scaling factor design based variable step size incremental resistance maximum power point tracking for PV systems," Journal of Power Electronics, Vol. 12, No. 1, pp. 164-171, Jan. 2012.

[13] A. M. Varnham, G. S. Virk, and D. Azzi, "Soft-computing model-based controllers for increased photovoltaic plant efficiencies," IEEE Trans. Energy Convers., Vol. 22, No. 4, pp. 873-880, Dec. 2007.

[14] A. G. Abo-Khalil, D. C. Lee, J. W. Choi, and H. G. Kim, "Maximum power point tracking controller connecting PV system to grid," Journal of Power Electronics, Vol. 6, No. 3, pp. 226-234, Jul. 2010.

[15] J. L. Agorreta, L. Reinaldos, R. Gonzalez, M. Borrega, J. Balda, and L. Marroyo, "Fuzzy switching technique applied to PWM boost converter operating in mixed conduction mode for PV systems," IEEE Trans. Ind. Electron., Vol. 56, No. 11, pp. 4363-4373, Nov. 2009.

[16] T. Esram and P. L. Chapman, "Comparison of photovoltaic array maximum power point tracking techniques," IEEE Trans. Energy Convers., Vol. 22, No. 2, pp. 439-449, Jun. 2007.

[17] M. A. G. D. Brito, L. Galotto, Jr., L. P. Sampaio, G. D. A. E. Melo, and C. A. Canesin, "Evaluation of the main MPPT techniques for photovoltaic applications," IEEE Trans. Ind. Electron., Vol. 60, No. 11, pp. 1156-1167, Mar. 2013.

[18] M. G. Villalva, J. R. Gazoli, and E. R. Filho, "Comprehensive approach to modeling and simulation of photovoltaic arrays," IEEE Trans. Power Electron., Vol. 24, No. 5, pp. 1198-1208, May. 2009.

[19] Y. Yushaizad, H. Siti, A. L. Muhammad, "Modeling and simulation of maximum power point tracker for photovoltaic system," National Power \& Energy Conf., pp. 88-93, Nov. 2004.

[20] A. Pandey, N. Dasgupta, and A. K. Mukerjee, "Design issues in implementing MPPT for improved tracking and dynamic performance," in Proc. IEEE IECON, pp. 4387-4391, 2006.

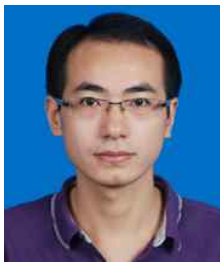

Yong Tian was born in Sichuan Province, China, in 1985. He received his B.S. and Ph.D degrees in Control Theory and Control Engineering from Chongqing University, Chongqing, China, in 2008 and 2012, respectively. He has been a Research Assistant in the Graduate School at Shenzhen, Tsinghua University since 2013. His current research interests include power electronics and control especially in renewable energy applications, battery management system, and wireless power transfer.

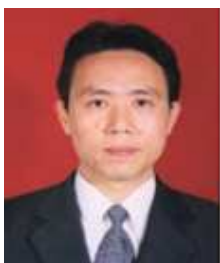

Bizhong Xia was born in Anhui Province, China, in 1969. He received his B.S. and M.S degrees in Mechanical Engineering from Chongqing University, China, in 1992 and 1995, respectively. He received his Ph.D. degree in Mechanical Engineering from Zhejiang University, China, in 2003. He served as a lecturer in the Graduate School at Shenzhen, Tsinghua University from 2006 to 2007. He has been an Associate Professor in the Graduate School at Shenzhen, Tsinghua University since 2008. His current research interests include power converter circuits, renewable energy generation, and electric machine control.

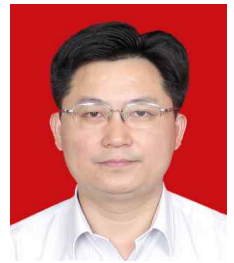

Zhihui Xu was born in Jiangsu Province, China, in 1970. He received his B.S. degree in Electrical Engineering from Huazhong University of Science and Technology, China, in 1993 and his M.S. degree in Computer Engineering from Tsinghua University, China, in 1995. He has been a Senior Electrical Engineer in Sunwoda Electronic Co. Ltd., China, since 2011. His current research interests include renewable energy generation, high-frequency power conversion techniques, and signal detection and processing.

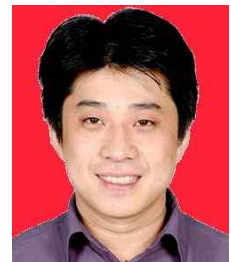

Wei Sun was born in Shanxi Province, China, in 1977. He received his B.S. degree in Automation from Harbin Engineering University, China, in 1999 and his M.S. degree in Investment Science from Renmin University of China, China, in 2005. He has been a Senior Electrical Engineer in Sunwoda Electronic Co. Ltd., China, since 2005. His current research interests include automation equipment and control, solar energy generation, and power quality. 